\title{
Functional characteristics and gene expression profiles of primary acute myeloid leukaemia cells identify patient subgroups that differ in susceptibility to histone deacetylase inhibitors
}

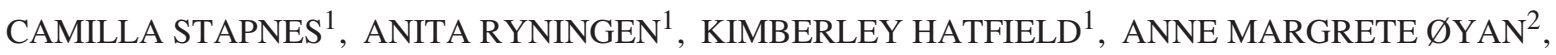 \\ GEIR EGIL EIDE ${ }^{3}$, MATTHIAS CORBASCIO ${ }^{4}$, KARL-HENNING KALLAND ${ }^{2}$,

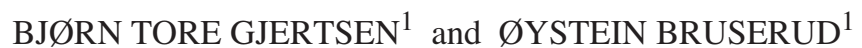

\begin{abstract}
${ }^{1}$ Institute of Medicine, University of Bergen and Division of Haematology, Department of Medicine, Haukeland University Hospital; ${ }^{2}$ The Gade Institute, University of Bergen and Department of Microbiology and Immunology, Haukeland University Hospital; ${ }^{3}$ Centre for Clinical Research, Haukeland University Hospital and Section for Epidemiology and Medical Statistics, Department of Public Health and Primary Health Care, University of Bergen;

${ }^{4}$ Department of Heart Diseases, Cardiothoracic Surgery, Haukeland University Hospital, Bergen, Norway
\end{abstract}

Received June 8, 2007; Accepted July 30, 2007

\begin{abstract}
Modulation of gene expression through histone deacetylase (HDAC) inhibition is considered a possible therapeutic strategy in acute myeloid leukaemia (AML). In vitro effects and basal gene expression of structurally different HDAC inhibitors were examined. Primary human AML cells were derived from 59 consecutive patients. The HDAC inhibitors valproic acid, PXD101, trichostatin A and sodium butyrate inhibited leukaemic and clonogenic cell proliferation and increased apoptosis in a dose-dependent manner when tested at high concentrations. However, at lower concentrations proliferation increased for a subset of patients. This divergence was also observed in the presence of all-trans retinoic acid, theophylline and decitabine, and in cocultures with bone marrow stromal cells. Levels of IL-1B, IL-6, GM-CSF and $\mathrm{TNF} \alpha$ increased. Based on the basal expression of 100 genes the patients with growth enhancement at intermediate HDAC inhibitor concentrations and those without this response were clustered into two mutually exclusive groups. Functional characterization and gene expression analyses identify AML patient subsets that differ in their response to HDAC inhibitors. These observations may explain why HDAC inhibitor therapy affects only a subset of patients.
\end{abstract}

\section{Introduction}

Acute myeloid leukaemia (AML) is an aggressive malignancy characterized by bone marrow accumulation of immature

Correspondence to: Dr Camilla Stapnes, Institute of Medicine, University of Bergen/Haukeland University Hospital, N-5021 Bergen, Norway

E-mail: camilla.ingvaldsen.stapnes@helse-bergen.no

Key words: acute myeloid leukaemia, histone deacetylase inhibitors, proliferation, gene expression leukaemia cells (1). The median age at the time of diagnosis is 60-65 years (1). Younger patients receiving the most intensive therapy (i.e. allotransplantation, high-dose cytarabine) have a median AML-free survival of $45-50 \%$, whereas patients above 60 years of age have lower survival because they generally have more genetic aberrations and also cannot receive intensive therapy due to an unacceptable risk of treatment-related mortality (1). This clearly demonstrates the need for new therapeutic strategies in AML, especially approaches with acceptable toxicity for the majority of elderly patients.

Therapeutic strategies targeting protein acetylation are now considered in many human malignancies, including AML (2). This can be achieved by inhibition of histone deacetylases (HDACs), a large group of enzymes that increase acetylation and thereby alters the function of a wide range of nuclear and cytoplasmic proteins $(1,3,4)$ including histones, transcription factors (5) and several regulators of cell proliferation, differentiation and apoptosis $(2,6,7)$. The first clinical studies report that HDAC inhibition can mediate antileukaemic effects for a subset of patients (reviewed in ref. 2). However, the optimal clinical use of these drugs (8) in future AML therapy will probably depend on better characterization of the biological effects, including pharmacological comparisons between patients. Previous studies have focused on the potential of HDAC inhibitors to differentiate AML cells (9). In the present study we therefore investigated the effects of structurally unrelated HDAC inhibitors on proliferation and viability of primary human AML cells derived from a large group of consecutive patients, and compared the gene expression profiles for patients who differed in their response to HDAC inhibitors in vitro.

\section{Materials and methods}

Cell donors and cell preparation. All the studies were approved by the local Ethics Committee (Region III, University of 
Bergen, Norway) and samples were collected after receiving informed consent.

Acute leukaemia cells were derived from a total of 59 randomly selected AML patients ( 25 females and 34 males, mean age at diagnosis 61 , range $28-82$ years) and 8 randomly selected acute lymphoblastic leukaemia (ALL) patients with high peripheral blood blast counts. Forty-three patients had de novo AML, the remaining minority had AML relapse (5 patients), chronic myeloid leukaemia in blast phase transformation (3 patients) or AML secondary to myelodysplasia ( 8 patients). The patients showed the following FAB classifications (10): M0, 5 patients; M1, 21 patients; M2, 11 patients; M3, 0 patients; M4, 17 patients; M5, 4 patients; and M6, 1 patient. Thirty-four patients had $>20 \% \mathrm{CD}^{+}$ blasts. Cytogenetic analysis performed for 43 patients showed abnormalities classified as described by Wheatley et al (11); $51 \%$ of the patients had no chromosomal aberrations, $12 \%$ had low-risk disease, $28 \%$ had high-risk and $9 \%$ had intermediaterisk abnormalities. Fifty patients were tested for genetic Fmsrelated tyrosine kinase 3 (FLT3) abnormalities (12); 17 had internal tandem duplications (ITD) and 3 had D835 or G835 mutations. Of the 8 ALL patients examined ( 3 females and 5 males, age range $27-78$ years) one had T-ALL and the others had B-ALL.

Normal bone marrow was obtained after informed consent from 4 random patients undergoing thoracotomy for cardiovascular disorders. None of these patients had haematological disorders.

Leukaemia peripheral blood mononuclear cells (PBMC) were isolated by density gradient separation (Ficoll-Hypaque; NycoMed, Oslo, Norway; specific density 1.077) from the peripheral blood of patients with a high percentage of leukaemia blasts among blood leukocytes, i.e. total leukocyte counts exceeding $20 \times 10^{9} / 1$ and at least $80 \%$ of the leukocytes being leukaemia blasts. Cells were stored frozen in liquid nitrogen $(12,13)$. The percentage of blasts among leukaemia PBMC exceeded $95 \%$ for all patients $(12,13)$, the contaminating cells being small lymphocytes.

$\mathrm{CD}_{3}{ }^{+}$cells were prepared from normal bone marrow or primary AML cells as described previously (14) (direct CD34 Progenitor cell isolation kit (MACS Cell Isolation; Miltenyi Biotec, Bergisch Gladbach, Germany). The percentage of CD34+ cells was determined by staining with a CD34PE(8G12) antibody (BD Biosciences, San Jose, CA) for flow cytometric analysis (FACS Calibur; BD Biosciences with CellQuest $^{\mathrm{TM}}$ Pro 4.0.1 and FlowJo ${ }^{\mathrm{TM}}$ 5.7.2 software). The CD34+ AML cells ( $\geq 95 \%$ purity) were dissolved in a volume corresponding to $10^{6}$ unseparated cells $/ \mathrm{ml}$.

Reagents for tissue culture. Recombinant human stem cell factor (SCF), granulocyte-macrophage colony stimulating factor (GM-CSF), interleukin 3 (IL-3) and FLT3 ligand (FLT3-L) were all supplied by PeproTech EC (London, UK) and used at $10 \mathrm{ng} / \mathrm{ml}$, unless otherwise stated. Culture medium was Stem Span SFEM ${ }^{\mathrm{TM}}$ (Stem Cell Technologies, Vancouver, BC, Canada) with $100 \mu \mathrm{g} / \mathrm{ml}$ of gentamicin (Garamycin ${ }^{\circledR}$; Schering-Plough AG, Berlin, Germany). Ten-percent heatinactivated foetal calf serum (FCS; BioWhittaker ${ }^{\mathrm{TM}}$, Cambrex Bio Science, Verviers, Belgium) (15) was added for the stromal cell cocultures.
Valproic acid (Orfiril ${ }^{\mathrm{TM}}$ ) was supplied by Destin $\mathrm{GmbH}$ (Hamburg, Germany) and PXD101 by Topo Target A/S (Copenhagen, Denmark) $(16,17)$. Trichostatin A (TSA), sodium butyrate and decitabine (2'-Deoxy-5-azacytidine) were purchased from Sigma-Aldrich Co. (St. Louis, MO). All-trans retinoic acid (ATRA, tretinoin) was obtained from Apotekproduksjon AS (Oslo, Norway) and theophylline (Tho-Dur ${ }^{\mathrm{TM}}$ ) from Astra Zeneca (London, UK).

\section{Assays for AML blast proliferation}

Suspension cultures. As described in detail previously $(12,14,15,18), 5 \times 10^{4}$ cells per well were cultured in a final volume of $200 \mu \mathrm{l}$ medium containing SCF+GM-CSF+IL-3 (referred to as cytokine-dependent proliferation in the following) in flat-bottomed 96-well microtiter plates (Nunclon $^{\mathrm{TM}} \Delta$ Surface; Nunc A/S Roskilde, Denmark). Cultures were incubated at $37^{\circ} \mathrm{C}$ in a humidified atmosphere of $5 \% \mathrm{CO}_{2}$. After six days $\left[{ }^{3} \mathrm{H}\right]$-thymidine $(37 \mathrm{kBq}$ per well; TRA 310, Amersham International, Amersham, UK) was added and nuclear radioactivity was assayed $18 \mathrm{~h}$ later. Cultures were harvested onto filter plates (UniFilter ${ }^{\circledR}-96$, GF/C ${ }^{\circledR}$; Perkin-Elmer Inc., Wellesley, MA), scintillation fluid was added (Microscint ${ }^{\mathrm{TM}}$; Perkin-Elmer Inc.) and nuclear radioactivity was measured (TopCount ${ }^{\circledR}$ NXTTM; Packard BioScience and Perkin-Elmer, Wellesley, MA). Negative controls were included in all experiments and corresponded to $<200 \mathrm{cpm}$.

Colony formation assay. Blasts were precultured with $\mathrm{SCF}+\mathrm{GM}-\mathrm{CSF}+\mathrm{IL}-3$ for one week in 24-well plates (Nunclon $^{\mathrm{TM}} \Delta$ Surface; Nunc A/S) with each well containing $1 \times 10^{6}$ cells in $1 \mathrm{ml}$ Stem Span. Cells were thereafter washed, resuspended in $1 \mathrm{ml}$ and $100 \mu \mathrm{l}$ of this cell suspension mixed with $0.9 \mathrm{ml}$ MethoCult GF H4434 (Stem Cell Technologies Inc., Vancouver, BC, Canada). The cells were cultured (duplicates, $0.5 \mathrm{ml}$ per well) for 14 days before the number of colonies containing more than 20 cells were determined by light microscopy (14).

Coculture of AML cells and normal bone marrow stromal cells. Normal human bone marrow stromal cells (BMSC) were derived from a healthy 20-year old female Caucasian (Poietics $^{\mathrm{TM}}$, Cambrex Bioscience, East Rutherford, NJ).

Cocultures were prepared as described $(13,14,18,19)$. Briefly, cultures were prepared in Transwell culture plates (Transwell ${ }^{\circledR} 3401$; Corning Incorporated, Costar ${ }^{\circledR}$, Corning, NY) where stromal cells $\left(2 \times 10^{4}\right.$ cells $)$ seeded in the lower large compartment were separated from the AML blasts $\left(10^{6}\right.$ cells $)$ in the upper small chamber of the same well by a semipermeable membrane with pore diameter of $0.4 \mu \mathrm{m}$ (1.5 ml medium + FCS in total per well) (18). Cultures were incubated for 3 days (cytokine analysis, viability studies) or 7 days $\left(\left[{ }^{3} \mathrm{H}\right]\right.$-thymidine incorporation assay: $280 \mathrm{kBq}$ per well after 6 days). Cultures were always terminated before the stromal cells were confluent.

Analysis of AML cell cytokine secretion. As described previously (13), 5x105 AML blasts per $1 \mathrm{ml}$ were cultured in 24-well tissue culture plates for $48 \mathrm{~h}$ before supernatants were harvested and cytokine levels determined. ELISA 

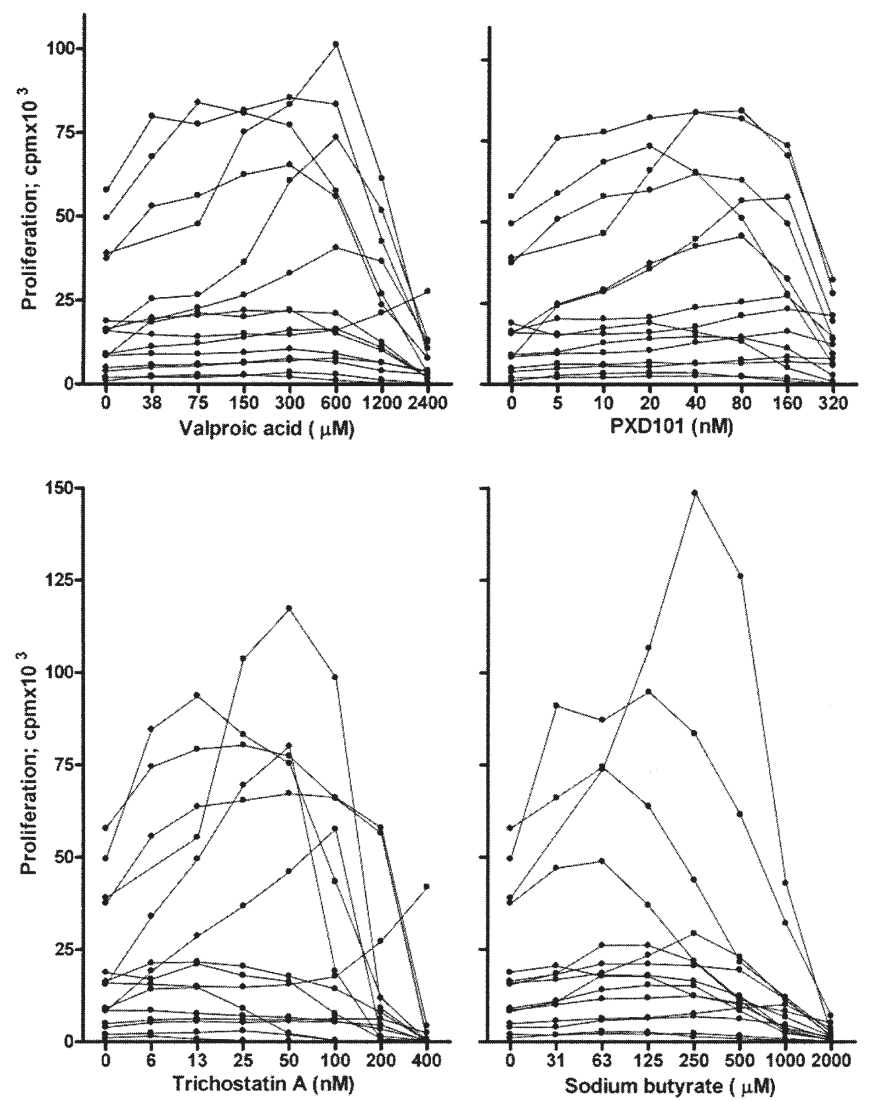

Figure 1. The effects of HDAC inhibitors on cytokine-dependent AML cell proliferation. Leukaemia cells derived from 16 consecutive patients were cultured without and with valproic acid, PXD101, TSA or butyrate. Proliferation was assayed as $\left[{ }^{3} \mathrm{H}\right]$-thymidine incorporation after 7 days of in vitro culture, and the results are presented as the mean cpm of triplicate determinations. Detectable proliferation was observed for 15 patients and only these results are presented in the figure. The standard deviation of the triplicates usually corresponded to $<10 \%$ of the corresponding mean.

analysis was used to determine levels of CXCL10 (IP-10) and CCL3 (MIP-1 $\alpha$ ) (Quantikine ${ }^{\circledR}$, R\&D Systems, Inc., Minneapolis, MN) and all other mediators were analysed by the Human Inflammatory 5-plex antibody bead kit and read on a Luminex 1000 instrument (BioSource International, Inc., Camarillo, CA). The minimal detectable levels were $10 \mathrm{pg} / \mathrm{ml} \mathrm{CCL3,} 3 \mathrm{pg} / \mathrm{ml} \mathrm{CXCL8} \mathrm{(IL-8),} 1.7 \mathrm{pg} / \mathrm{ml} \mathrm{CXCL10,}$ $15 \mathrm{pg} / \mathrm{ml} \mathrm{GM-CSF}, 15 \mathrm{pg} / \mathrm{ml} \mathrm{IL}-13,3 \mathrm{pg} / \mathrm{ml} \mathrm{IL}-6$ and $10 \mathrm{pg} / \mathrm{ml}$ $\mathrm{TNF} \alpha$.

Analysis of AML cell viability during in vitro culture. The percentages of viable, apoptotic and necrotic cells were determined by flow cytometric analysis of Annexin V-FITC and propidium iodide (PI) (Apoptest ${ }^{\mathrm{TM}}$ - FITC kit; NeXins Research, Kattendijke, The Netherlands) stained cells as described in a previous methodological study (19). Four different cell populations were identified: viable (double negative), early apoptotic and apoptotic (only Annexin positive) and necrotic (double positive). Our results are presented as the percentage of viable cells (19).

Gene expression analysis. The Agilent Human Whole Genome $44 \mathrm{k}$ oligonucleotide microarray (Agilent Technol., Inc., Palo Alto, CA, USA) was used according to the manufacturer's protocols, except for a more stringent wash (0.1X SSC at $35^{\circ} \mathrm{C}$ for $\left.10 \mathrm{~min}\right)$. Feature extraction, normalization, flooring and filtration of data were performed as previously described (20-22). Microarray data were formatted in a J-Express-file suitable for data mining (http://www.molmine.com/). The Feature Subset Selection method (FSS), p-value score method and individual ranking selected subsets of genes that distinguished treatment Group 1 (divergent and dosedependent drug effects) and Group 2 (only growth inhibition). The Principal Component Analysis (PCA) module of J-Express was used to visualize the discrimination classes based on 100 genes.

Presentation of the data. $\left[{ }^{3} \mathrm{H}\right]$-thymidine incorporation was assayed in triplicates and the mean counts per minute (cpm) used for all calculations. Detectable blast proliferation was defined as $\left[{ }^{3} \mathrm{H}\right]$-thymidine incorporation exceeding $1000 \mathrm{cpm}$ $(12,15,18)$. A significant alteration of proliferation for an individual patient was defined as a difference in incremental responses exceeding $2000 \mathrm{cpm}$, and the difference in cpm being $>20 \%$ of the control response. Incremental response was analysed using three-way repeated measures analysis of variance (ANOVA) of ln-transformed mean values of cpm with respect to dose (control, intermediate and high dose for each drug), HDAC inhibitors (valproic acid, PXD101, TSA and butyrate) and additional drugs (ATRA, decitabine and theophylline). Alterations in cytokine concentrations, ALL and $\mathrm{CD} 34^{+}$cell proliferation were assessed by one-way repeated measures ANOVA with Dunnett's multiple comparison test. Differences were regarded as significant when $p<0.05$. All these statistical analyses were performed using SPSS 13.0 software. Wilcoxon's test for paired samples was used for statistical comparisons of colony formation and viability data (GraphPad Prism 4 software).

\section{Results}

HDAC inhibitors decreased AML cell proliferation at high concentrations but caused growth enhancement for a subset of patients at lower concentrations. AML cells derived from 16 consecutive patients were cultured with various concentrations of valproic acid, PXD101, TSA and sodium butyrate. Detectable proliferation was observed for 15 patients (Fig. 1). All four drugs had dose-dependent effects: i) low concentrations usually had a minor impact on blast proliferation; ii) intermediate concentrations had divergent effects, and increased proliferation was observed for a subset of patients; and iii) high concentrations caused an inhibition of proliferation for all except one patient. Based on these results we therefore selected 3 different concentrations of valproic acid $(38,600$ and $2400 \mu \mathrm{M}), \operatorname{PXD} 101(5,80$ and $1000 \mathrm{nM})$, TSA $(6,50$ and $400 \mathrm{nM})$ and sodium butyrate $(31,250$ and $2000 \mu \mathrm{M})$ that were used in the following experiments.

AML cells derived from 53 patients were cultured and prepared without and with valproic acid. Detectable proliferation in either drug-free or drug-containing cultures was observed for 47 patients. Valproic acid had dose-dependent effects on AML cell proliferation (Fig. 2, Table I). Firstly, the lowest concentration usually had minor effects (results omitted in figure) where significant inhibition was observed 

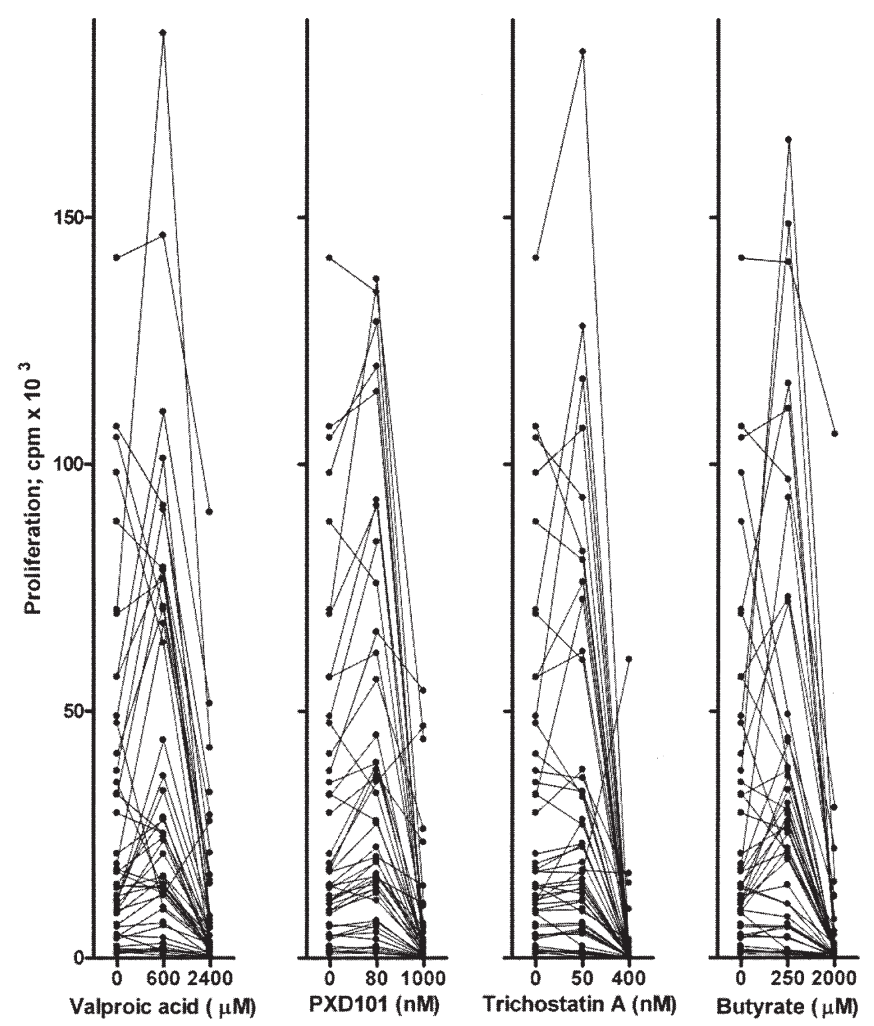

Figure 2. The effect of HDAC inhibitors on cytokine-dependent AML cell proliferation. Studies of 53 consecutive patients. Low, intermediate and high concentrations were tested both for valproic acid, PXD101, TSA and butyrate, but the figure presents the results only for the intermediate and high concentrations. Detectable proliferation in drug-free controls was observed for 47 patients, 1 additional patient showed detectable proliferation in certain drugcontaining cultures. Proliferation was assayed as $\left[{ }^{3} \mathrm{H}\right]$-thymidine incorporation after 7 days of in vitro culture, and the results are presented as the mean cpm of triplicate determinations. The standard deviation of the triplicates usually corresponded to $<10 \%$ of the corresponding mean.

for 4 patients and an enhancement for 3 patients only. Secondly, $600 \mu \mathrm{M}$ valproic acid increased proliferation (the difference corresponding to $>2000 \mathrm{cpm}$ and $>20 \%$ of the control) for 20 patients, and an inhibition was then detected only for 8 patients. Finally, the highest concentration caused decreased or unchanged proliferation for all except one patient, and for 36 patients this inhibition corresponded to $>20 \%$ of the drugfree control with an absolute value of at least $2000 \mathrm{cpm}$.

PXD101, TSA and sodium butyrate were also investigated for the same patients and similar effects were observed for all the HDAC inhibitors (Fig. 2, Table I). The statistical significance of the interaction of drugs and doses was tested in a three-way repeated measures ANOVA, and all findings were highly significant $(\mathrm{p}<0.01)$, indicating an overall effect of the drugs and different doses on the majority of AML cells. A significant growth enhancement by intermediate drug concentrations was detected with at least 3 HDAC inhibitors for 19 patients ( 5 patients showing enhancement for all 4 drugs); but was not detected with any drug for 16 patients and with only one drug for 8 patients. Thus, $40 \%$ of the AML patients constitute a distinct subset where intermediate concentrations of structurally different HDAC inhibitors commonly cause enhanced proliferation. This was reproducible for the individual AML sample.
Table I. Effects of HDAC inhibitors on in vitro proliferation of native human AML cells; a summary of the results.

\begin{tabular}{lrrr}
\hline & & \multicolumn{2}{c}{$\begin{array}{c}\text { Pharmacological effect on } \\
\text { AML cell proliferation }\end{array}$} \\
\cline { 3 - 4 } HDAC inhibitor & Concentration & Increased & Decreased \\
\hline Valproic acid & $38 \mu \mathrm{M}$ & $3 / 40$ & $4 / 40$ \\
& $600 \mu \mathrm{M}$ & $\mathbf{2 0 / 4 7}$ & $8 / 47$ \\
& $2400 \mu \mathrm{M}$ & $1 / 47$ & $\mathbf{3 6 / 4 7}$ \\
PXD101 & $5 \mathrm{nM}$ & $5 / 39$ & $2 / 39$ \\
& $80 \mathrm{nM}$ & $\mathbf{2 5 / 4 6}$ & $2 / 46$ \\
TSA & $1000 \mathrm{nM}$ & $2 / 43$ & $\mathbf{3 4 / 4 3}$ \\
& $6 \mathrm{nM}$ & $6 / 38$ & $2 / 38$ \\
& $50 \mathrm{nM}$ & $\mathbf{1 0 / 4 7}$ & $6 / 47$ \\
Sodium butyrate & $31 \mu \mathrm{M}$ & $\mathbf{1 2 / 3 7}$ & $\mathbf{3 9 / 4 7}$ \\
& $250 \mu \mathrm{M}$ & $\mathbf{1 8} / \mathbf{4 6}$ & $\mathbf{1 0} / \mathbf{4 6}$ \\
& $2000 \mu \mathrm{M}$ & $0 / 47$ & $\mathbf{4 1 / 4 7}$ \\
\hline
\end{tabular}

Native human AML cells derived from a total of 53 consecutive patients were cultured in vitro for 7 days before cytokine-dependent proliferation was assayed by $\left[{ }^{3} \mathrm{H}\right]$-thymidine incorporation. Increased or decreased proliferation was defined as a difference in cpm corresponding to at least $20 \%$ of the drug-free control and having an absolute value $>2000 \mathrm{cpm}$. The results are presented as the number of patients with increased or decreased proliferation relative to the number of patients with detectable proliferation in drug-free controls. Values representing at least $20 \%$ of the patients are marked in bold.

The degree of inhibition when testing high concentrations and the growth enhancement at intermediate concentrations showed no correlation to patient age, AML cell differentiation (FAB classification), CD34 expression or genetic abnormalities (data not shown).

HDAC inhibitors had dose-dependent effects on AML blast proliferation in the presence of ATRA, decitabine and theophylline. HDAC inhibitors are combined with ATRA, decitabine or theophylline in clinical studies $(23,24)$, and we therefore investigated whether the dose-dependent effects of HDAC inhibitors were maintained in the presence of these drugs. Choosing concentrations at clinically relevant serum levels, we examined $1.1 \mu \mathrm{M}$ ATRA, $109 \mathrm{nM}$ decitabine and $100 \mu \mathrm{M}$ theophylline alone on cytokine-dependent proliferation for the 53 consecutive patients. All three drugs were in addition combined with intermediate and high concentrations of valproic acid (600 and $2400 \mu \mathrm{M})$, PXD101 (80 and $1000 \mathrm{nM})$, TSA (50 and $400 \mathrm{nM}$ ) and sodium butyrate $(250$ and $2000 \mu \mathrm{M})$.

The median cell proliferation in drug-free controls was $14710 \mathrm{cpm}$ (range 904-141800). ATRA, decitabine and theophyllin alone had divergent effects on AML cell proliferation (data not shown). The growth enhancement caused by intermediate drug levels could still be detected for the same 

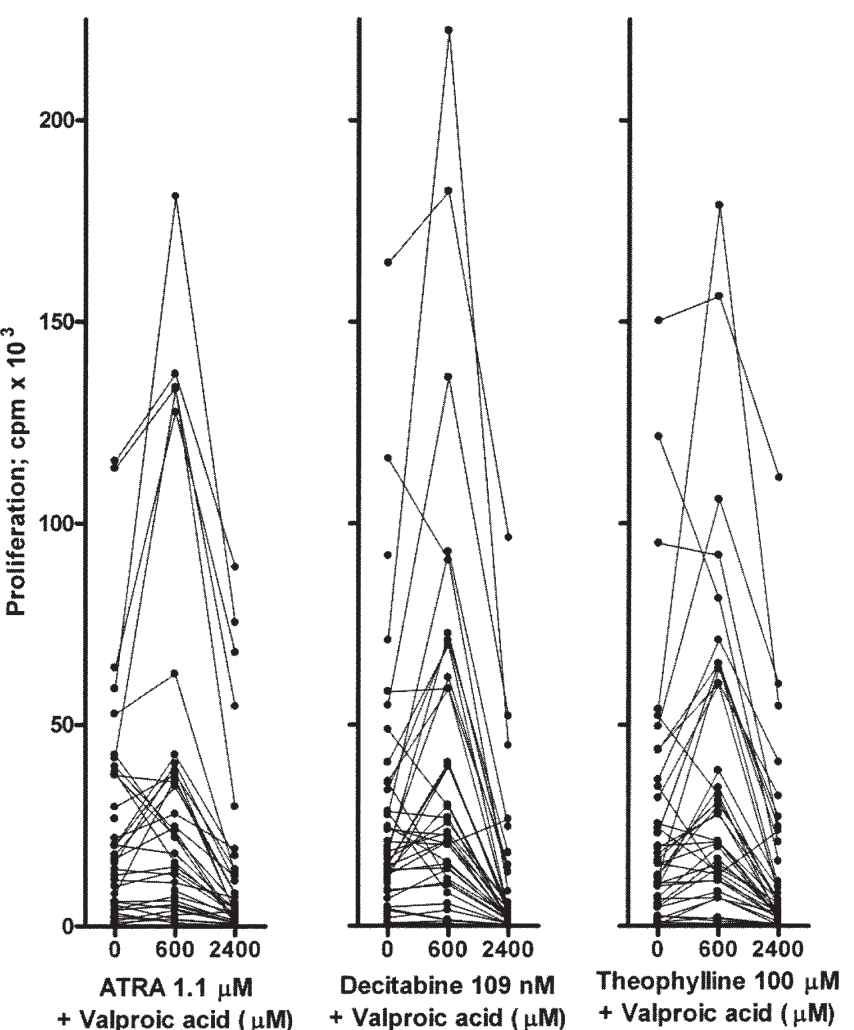

Figure 3. The effect of valproic acid in the presence of ATRA, decitabine or theophylline. AML cells derived from 53 consecutive patients were examined, but the figure presents the results only for those patients with detectable proliferation. Proliferation was assayed as $\left[{ }^{3} \mathrm{H}\right]$-thymidine incorporation after 7 days of in vitro culture, and the results are presented as the mean cpm of triplicate determinations. The standard deviation of the triplicates usually corresponded to $<10 \%$ of the corresponding mean.

subset of patients in the presence of ATRA/decitabine/ theophylline, whereas high concentrations of HDAC inhibitors caused growth inhibition (Fig 3; p<0.05). Thus, AML cells differ in their response to HDAC inhibitors even in the presence of other drugs.

HDAC inhibitors had dose-dependent effects on AML cell colony formation, viability and cytokine secretion. The $\left[{ }^{3} \mathrm{H}\right]-$ thymidine incorporation assay is based on 7 days of culture in suspension culture with enrichment of long-term proliferating clonogenic cells (25). We therefore investigated the effect of valproic acid and PXD101 on AML colony formation for 12 consecutive patients. The number of colonies in drug-free controls showed a wide variation between patients (Fig. 4A). At intermediate concentrations ( $600 \mu \mathrm{M}$ and $80 \mathrm{nM}$, respectively) 11 of the AML samples treated with valproic acid $(p=0.003)$ and 6 treated with PXD101 (not significant) showed increased colony formation. Reduced colony numbers were observed for a majority of patients when testing higher concentrations of valproic acid (2400 $\mu \mathrm{M}$; not significant) and PXD101 (1000 nM; $\mathrm{p}=0.004)$. For 7 patients we detected colonies with morphological signs of erythroid differentiation in our assay $(12,26)$, but the fraction of erythroid colonies and the colony morphology were not significantly altered by the HDAC inhibitors (data not shown).

AML cells derived from 14 unselected patients were incubated in medium alone or medium with valproic acid
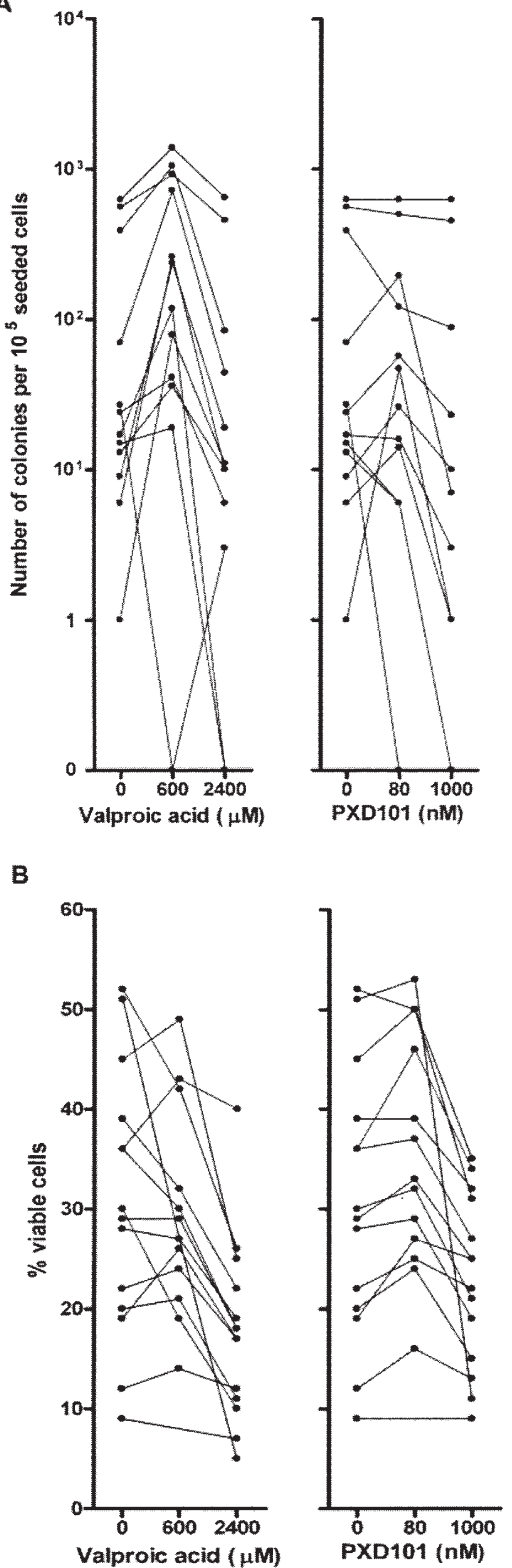

Figure 4. (A) Upper panel. The effects of valproic acid and PXD101 on AML cell colony formation. AML blasts derived from 12 consecutive patients were cultured in medium alone and medium containing valproic acid or PXD101. After 7 days of preculture in cytokine-dependent suspension cultures, the number of colonies was determined in a drug-free colony formation assay. Colony formation in controls was observed for all patient samples. The results are presented as the total number of colonies (colonies containing $>20$ cells; means of duplicate determinations) per 50000 seeded cells (of the original $10^{6}$ AML cells in the drug-containing suspension cultures). (B) Lower panel. The effects of valproic acid and PXD101 on AML cell viability. AML blasts derived from 14 consecutive patients were cultured for $48 \mathrm{~h}$ in medium alone and medium containing valproic acid or PXD101. The percentage of viable cells (double negative) was determined by flow cytometric analysis of Annexin and PI stained cells

(600 and $2400 \mu \mathrm{M}$ ) and PXD101 (80 and $1000 \mathrm{nM}$ ). Viability (Annexin $\mathrm{V}^{-} / \mathrm{PI}^{-}$) was unaltered or increased (overall results not significant) for intermediate concentrations, whereas a decreased percentage of viable cells was observed after $48 \mathrm{~h}$ of incubation in the presence of high drug concentrations $(\mathrm{p}<0.001$ for valproic acid and $\mathrm{p}=0.002$ for PXD101) (Fig 4B). These results were reproduced in independent experiments for 4 patients (data not shown). We also determined AML 
Table II. Cytokine-levels in cocultures of AML cells and BMSC; a summary of the results of 8 consecutive AML patients.

\begin{tabular}{|c|c|c|c|c|}
\hline \multirow[b]{2}{*}{ Cytokine } & \multirow[b]{2}{*}{ Drug-free controls } & \multicolumn{3}{|c|}{ Cytokine concentration (pg/ml) } \\
\hline & & $600 \mu \mathrm{M}$ valproic acid & $2400 \mu \mathrm{M}$ valproic acid & 1000 nM PXD101 \\
\hline IL-1ß & $96 \pm 22$ & $188 \pm 22^{a}$ & $158 \pm 23^{a}$ & $190 \pm 32^{a}$ \\
\hline GM-CSF & $187 \pm 43$ & $360 \pm 43^{a}$ & $299 \pm 41^{\mathrm{a}}$ & $307 \pm 43^{a}$ \\
\hline IL-6 & $4648 \pm 1596$ & $10845 \pm 1582^{\mathrm{a}}$ & $8791 \pm 1735^{a}$ & $8828 \pm 1810^{a}$ \\
\hline $\mathrm{TNF} \alpha$ & $14 \pm 4$ & $46 \pm 15^{\mathrm{a}}$ & $29 \pm 10$ & $36 \pm 12$ \\
\hline CCL3 & $263 \pm 143$ & $4205 \pm 2294$ & $4067 \pm 2512$ & $5369 \pm 3224$ \\
\hline CXCL8 & $8848 \pm 4773$ & $10106 \pm 1239$ & $8745 \pm 1150$ & $9455 \pm 1096$ \\
\hline CXCL10 & $824 \pm 711$ & $710 \pm 535$ & $408 \pm 360$ & $352 \pm 303$ \\
\hline
\end{tabular}

Native human AML cells derived from 8 consecutive patients were cultured in vitro in cocultures with BMSC for 3 days before supernatants were harvested and cytokines assayed. The results are presented as mean \pm standard error of the mean for the 8 patients, and significant results ( ${ }^{\mathrm{a}} \mathrm{p}<0.01$; one-way repeated measures ANOVA with Dunnett's multiple comparison test).

cell viability after 7 days of in vitro culture (11 patients) in the presence of exogenous SCF+GM-CSF+IL-3, and $1000 \mathrm{nM}$ PXD101 reduced viability significantly $(\mathrm{p}=0.009)$ (data not shown).

We investigated the effects of intermediate and high concentrations of valproic acid and PXD101 on the constitutive cytokine release by primary AML blasts derived from 13 consecutive patients. The levels of selected chemokines (CCL3, CXCL8 and CXCL10), haematopoietic growth factors (IL-1ß, GM-CSF) and immunoregulatory cytokines (IL-6, TNF $\alpha$ ) were examined. Most cytokines showed a wide variation that was maintained also in the presence of HDAC inhibitors, and when comparing the overall results for each cytokine no statistically significant difference was observed (data not shown).

HDAC inhibitors had dose-dependent effects on AML cell proliferation in the presence of bone marrow stromal cells. The effect of valproic acid (600 and $2400 \mu \mathrm{M})$ and PXD101 (1000 nM) on 8 consecutive patients' AML cells cultured with BMSC in Transwell ${ }^{\mathrm{TM}}$ cocultures was examined. High drug concentrations decreased both proliferation (valproic acid 6/8; PXD101 5/8) and viability (valproic acid 8/8; PXD101 $7 / 8)$. Intermediate levels of valproic acid had either no impact or increased proliferation (3/8) and viability (3/8). We also investigated the effect of valproic acid and PXD101 on cytokine levels in these cocultures (Table II). The drugs increased GM-CSF, IL-1ß, IL-6 levels and TNF $\alpha(600 \mu \mathrm{M}$ valproic acid only). The chemokine levels were not significantly altered. However, there was still a wide variation in cytokine levels between patients, and a similar variation was also maintained in the presence of HDAC inhibitors.

Effects of HDAC inhibitors on leukaemic and normal CD34+ cells. Highly enriched CD34+ AML cells from 8 patients that showed growth enhancement when testing intermediate concentrations of HDAC inhibitors were prepared. We investigated intermediate and high concentrations of valproic acid and PXD101. Strong cytokine-dependent proliferation by the CD34+ AML cells was only detected for a subset of the patients, and growth enhancement by intermediate concentrations and inhibition by high concentrations were then observed for several samples (Table III). Thus, HDAC inhibitors exhibited concentration-dependent differences even for the $\mathrm{CD} 34^{+} \mathrm{AML}$ cell subset.

Cytokine-dependent proliferation of normal CD34+ bone marrow cells from 4 individuals was also tested. Growth enhancement was observed for $600 \mu \mathrm{M}$ valproic acid $(\mathrm{p}<0.05)$, whereas $2400 \mu \mathrm{M}$ valproic acid and $1000 \mathrm{nM}$ PXD101 did not alter the growth (Table III). Thus, the effects of HDAC inhibitors on normal $\mathrm{CD} 34^{+}$haematopoietic cells differ from those on the AML cells.

HDAC inhibitors decreased ALL blast proliferation. The effect of valproic acid, PXD101, TSA and sodium butyrate on cytokine-dependent (SCF+IL-3+FLT3-L, all $5 \mathrm{ng} / \mathrm{ml}$ ) ALL blast proliferation was assayed for 8 unselected patients. All drugs were tested at 3 different concentrations (low, intermediate, and high). Two patients did not show detectable proliferation in any culture, but for all the other 6 patients dose-dependent growth inhibition was observed. Growth enhancement was not detected for any patient (data not shown). Drug-induced growth inhibition was also observed in the presence of $110 \mathrm{nM}$ decitabine (data not shown).

Patients without and with HDAC inhibitor-induced growth enhancement were distinguished by different gene expression profiles. The global gene expression profiles were investigated for a group of 17 FLT3-ITD ${ }^{+}$patients with normal cytogenetics in order to generate a more homogenous study group in respect to gene abberations. These patients were divided into two groups: 11 patients showing AML growth enhancement when testing intermediate concentrations of at least 3 different HDAC inhibitors (group 1) and 6 patients with no growth enhancement for any HDAC inhibitor (Group 2). Both groups showed growth inhibition when testing high drug concentrations. The two groups could not be separated using FSS analysis of microarray expression data of HDACs and histone acetyl transferases (data not shown). However, an individual ranking and PCA analysis based on 100 genes 


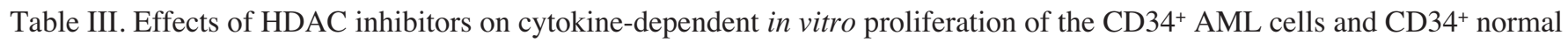
bone marrow cells.

\begin{tabular}{|c|c|c|c|c|c|c|}
\hline \multirow[b]{2}{*}{ Patients } & \multirow[b]{2}{*}{$\begin{array}{c}\mathrm{CD}^{3} 4^{+} \text {cells among } \\
\text { AML cells }(\%)\end{array}$} & \multicolumn{5}{|c|}{$\left[{ }^{3} \mathrm{H}\right]$-thymidine incorporation (cpm) } \\
\hline & & Drug-free control & $\begin{array}{c}600 \mu \mathrm{M} \\
\text { valproic acid }\end{array}$ & $\begin{array}{c}2400 \mu \mathrm{M} \\
\text { valproic acid }\end{array}$ & $\begin{array}{c}80 \mathrm{nM} \\
\text { PXD101 }\end{array}$ & $\begin{array}{l}1000 \mathrm{nM} \\
\text { PXD101 }\end{array}$ \\
\hline A & 55 & $3502 \pm 95$ & $12690 \pm 1338$ & $4781 \pm 792$ & $5474 \pm 355$ & $1790 \pm 139$ \\
\hline B & 19 & $2074 \pm 222$ & $1089 \pm 185$ & $363 \pm 37$ & $814 \pm 80$ & $319 \pm 42$ \\
\hline $\mathrm{C}$ & 17 & $1000 \pm 52$ & $1332 \pm 60$ & $768 \pm 55$ & $1294 \pm 124$ & $874 \pm 66$ \\
\hline $\mathrm{D}$ & 90 & $24969 \pm 521$ & $55341 \pm 2788$ & $4542 \pm 893$ & $38566 \pm 368$ & $328 \pm 10$ \\
\hline $\mathrm{E}$ & 2 & $24010 \pm 2171$ & $42157 \pm 2741$ & $2468 \pm 192$ & $37215 \pm 3868$ & $281 \pm 56$ \\
\hline $\mathrm{F}$ & 68 & $364 \pm 92$ & $1005 \pm 73$ & $387 \pm 135$ & $452 \pm 124$ & $228 \pm 15$ \\
\hline Normal CD34+ cells & - & $21900 \pm 5920$ & $86570 \pm 38510$ & $28920 \pm 10310$ & $41930 \pm 16710$ & $2485 \pm 700$ \\
\hline
\end{tabular}

$\mathrm{CD}_{4}{ }^{+}$native human AML cells derived from 8 patients showing growth enhancement when testing intermediate HDAC inhibitor concentrations and normal bone marrow cells derived from 4 individuals (the mean values of the four individuals are reported) were prepared and cultured for 7 days. The $\mathrm{CD}^{2} 4^{+} \mathrm{AML}$ cells were dissolved in a volume corresponding to $10^{6}$ unseparated cells $/ \mathrm{ml}$ and then tested for proliferation by $\left[{ }^{3} \mathrm{H}\right]$-thymidine incorporation. The results are presented as the mean $\mathrm{cpm} \pm$ standard error of the mean of triplicate determinations. For 2 patients detectable proliferation was not observed in any culture, and therefore are not presented. The values shown in bold represent alteration from or to detectable proliferation $(>1000 \mathrm{cpm})$, or a difference having an absolute value $>2000 \mathrm{cpm}$ and being $>20 \%$ of the corresponding drug-free control.

clearly separated the two groups. The false discovery rate of the first 100 genes was $26 \%$ with p-values from $4.9 \times 10^{-9}$ to 0.001 . The PCA plot is shown in Fig. 5A. The most discriminating genes that divided the groups into two mutually exclusive gene profile clusters are summarized in Fig. 5B.

Several of the genes have previously been used for classification of AML patients. Firstly, high expression of Dynein light chain 1 (DLC1) and low expression of transmembrane 4 superfamily member 2 (TM4SF2) are associated with bad prognosis (27); DLC1 showed high expression in our patients with drug-induced growth enhancement whereas high TM4SF2 expression was observed for those without growth enhancement. Secondly, low expression of members of the apolipoprotein system has been associated with adverse prognosis (27), and our patients with growth enhancement also showed low levels of Apolipoprotein C1 (APOC1). Finally, high Fc-fragment of IgG receptor transporter $\alpha$ (FCGRT) expression is associated with in vitro differentiation in response to ATRA and vitamin D (28), and increased expression was observed for our patients without drug-induced growth enhancement. Collectively these observations suggest that our identification of two major subsets may be clinically relevant.

\section{Discussion}

HDAC inhibitors are explored in the treatment of AML alone or in combination with other noncytotoxic drugs $(2-4,29)$. However, the functional effects of these drugs on proliferation and viability of primary human AML cells have not been characterized in detail. In the present study we therefore compared four structurally different HDAC inhibitors: valproic acid is a modified fatty acid, similarly sodium butyrate is an aliphatic fatty acid and TSA and PXD101 are hydroxamic acid derivatives $(16,30,31)$. Our present results demonstrate that all four drugs show similar effects in individual patients, but that the effects differ between patients.

Previous studies of HDAC inhibitors in AML have investigated effects on differentiation of the leukaemic cells $(9,26)$. In the present study we therefore focused on the effects on proliferation, viability and clonogenicity. Our in vitro assay with $\left[{ }^{3} \mathrm{H}\right]$-thymidine incorporation after seven days culture reflects an enrichment of clonogenic cells (25). In a recent study Ryningen et al (26) described minor effects of HDAC inhibitors on expression of differentiation markers in AML blasts. This is consistent with our present observations, where HDAC inhibitors did not alter the morphology for erythroid and nonerythroid colonies, or the ratio between the types of colonies.

We included patients with high peripheral blood blast counts. This technique has a minimal risk of inducing functional alterations in the blasts $(13,15)$, but a high degree of leukaemisation may reflect biological differences (12) and thereby make our results representative only for this particular patient subset.

Based on initial dose-response experiments we selected the drug concentrations that were used when investigating a group of 53 consecutive patients, focusing on cytokinedependent proliferation because AML development takes place in a microenvironment where exogenous growth factors are available from neighbouring stromal cells $(13,18,19,30,31)$. The results demonstrated that all 4 HDAC inhibitors had antiproliferative action against native human AML cells when tested at the highest concentrations. At lower concentrations increased proliferation was observed for a large subset of patients. This effect was observed for all HDAC inhibitors and also with valproic acid for the clonogenic AML cell subset, and 
A

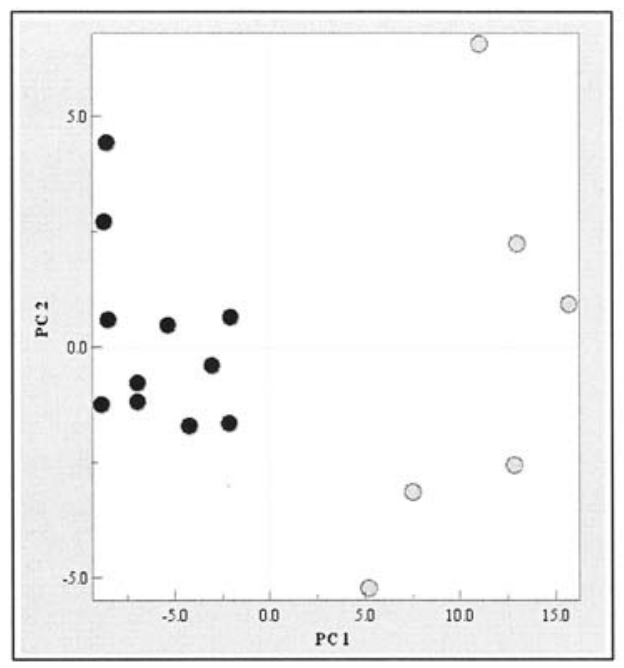

Group $1 \bullet$
Group 20

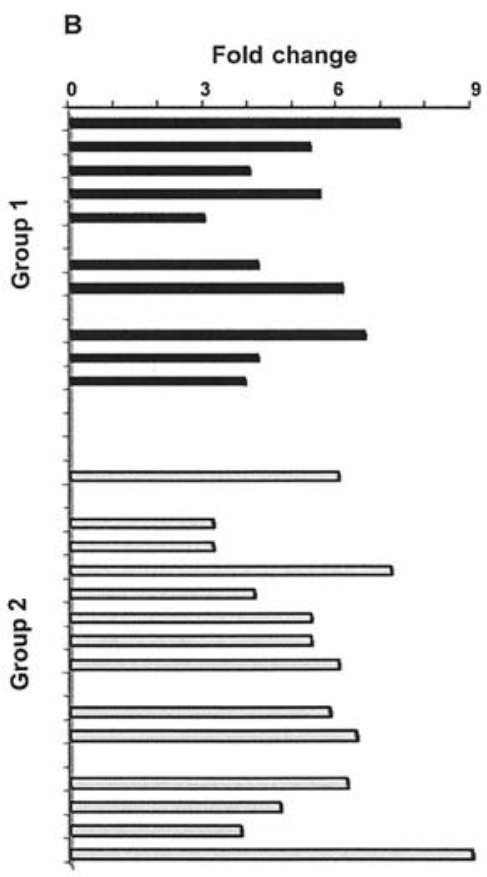

$\begin{array}{lll}\text { Symbol } & \text { GenBank } & \text { Description } \\ & & \\ \text { JARID3 } & \text { NM_004973 } & \text { Cell cycle } \\ \text { DLC1 } & \text { NM_006094 } & \\ \text { WDR35 } & \text { NM_020779 } & \\ \text { DDX32 } & \text { NM_018180 } & \\ \text { BAG2 } & \text { NM_004282 } & \text { Apoptosis } \\ \text { ABCA5 } & \text { NM_018672 } & \text { Transporters } \\ \text { FLIPT1 } & \text { NM_018420 } & \\ \text { HP } & \text { AF026219 } & \text { Homeostasis } \\ \text { AGPAT4 } & \text { AL1212123 } & \text { Acyltransferase } \\ \text { COCH } & \text { BC007230 } & \text { Sensory perseption } \\ & & \\ & & \\ \text { DFNA5 } & \text { NM_004403 } & \text { Response to DNA damage, } \\ & & \text { p53 dependent } \\ \text { MAD1 } & \text { NM_003550 } & \text { Cell cycle } \\ \text { SMAD3 } & \text { NM_005902 } & \\ \text { PTK2 } & \text { NM_005507 } & \\ \text { SERPINF1 } & \text { NM-002615 } & \\ \text { PIG13 } & \text { BC028567 } & \\ \text { TSPAN7 } & \text { NM_004615 } & \\ \text { IL12RB2 } & \text { NM_001559 } & \\ \text { KCNA3 } & \text { NM_002232 } & \text { Apoptosis } \\ \text { AKT3 } & \text { BC019085 } & \\ \text { NDRG2 } & \text { AF087872 } & \text { Development } \\ \text { LHX3 } & \text { NM_014368 } & \\ \text { EID3 } & \text { AK098698 } & \\ \text { LAG3 } & \text { NM_002286 } & \text { Lymphocyte activation }\end{array}$

Figure 5. Global gene expression profiles in AML cells with and without HDAC inhibitor-associated growth enhancement. (A) Upper panel. Separation of treatment group 1 (dark symbols, growth enhancement) and group 2 (light symbols, no growth enhancement) based on the gene expression profiles of 100 preselected genes visualized by PCA. For visualization in a two-dimensional plot, the first two principal components were chosen as they captured most of the variation in the original data set. (B) Lower panel. Gene annotations associated with highly expressed genes that significantly discriminate between the two treatment groups. Selected genes with fold change $>3.0$ are shown and abbreviations represent gene symbols. Dark bars represent group 1 and light bars represent group 2. Group 1: JARID2, Jumonji AT-rich interactive domain 2; $D L C 1$, Dynein light chain 1; WDR35, WD repeat domain 35; DDX32, DEAD/H helicase-like protein-1; $B A G 2$, BCL2-associated athanogene 2; ABCA5, ATP-binding cassette, subfamily A (ABC1) 5; FLIPT1, Fly-like putative organic ion transporter 1; HP, Haptoglobin precursor; AGPAT4, 1-acylglycerol-3-phosphatase acyltransferase 4; $C O C H$, Coagulation factor $\mathrm{C}$ homolog, cochlin. Group 2: DFNA5, Deafness, autosomal dominant 5; MAD1, mitotic arrest deficient-like 1; SMAD3, Mothers against decapentaplegic homolog 3; PTK2, protein tyrosine kinase 2; SERPINF1, Serine (or cysteine) proteinase inhibitor, clade F; PIG13, Proliferation-inducing gene 13 protein 13; TSPAN7, T-cell acute lymphoblastic leukemia associated antigen 1; IL12RB2, Interleukin 12 receptor $ß 2 ; K C N A 3$, Voltage-gated potassium channel subunit Kv1.3; AKT3, v-akt murine thymoma viral oncogene homolog 3; NDRG2, N-myc downstream regulator 2; LHX6, LIM homeobox 6; EID3, EP300 interacting inhibitor of differentiation 3; LAG3, Lymphocyte activation gene 3 .

for $\mathrm{CD}_{34}{ }^{+} \mathrm{AML}$ cells that usually include the most immature leukaemic stem cells (25). The most likely explanation for this concentration-dependent variation is that HDAC inhibitors differ in their affinity to the various HDACs $(30,31)$. This may give some explanation as to why HDAC inhibitors have produced very moderate responses in patients, and even increased peripheral blood blast counts in some patients $(2,9,32-34)$. 
Several clinical studies have combined HDAC inhibitors with ATRA, decitabine (35) or theophylline (2). ATRA is used for differentiation induction in acute promyelocytic leukaemia (36) and has biological (although not clinically important) effects also in other variants of AML (37). Low-dose decitabine demethylates DNA and thus increases the availability for transcription (2). Theophylline can increase intracellular levels of cyclic AMP and may thereby cause decreased proliferation and increased susceptibility to differentiation inducing therapy (38). The divergent results at intermediate HDAC inhibitor concentrations and the antiproliferative impact at higher concentrations were maintained also when HDAC inhibitors were tested in the presence of ATRA, decitabine or theophylline. Similar dose-dependent differences were detected in the presence of nonleukaemic stromal cells. Furthermore, unaltered or increased AML cell viability was observed when testing intermediate concentrations, whereas viability decreased when testing higher concentrations. Finally, the concentrationdependent effects of HDAC inhibitors were independent of the patient's clinical characteristics or the AML cells' biological characteristics. In conclusion, even though previous studies have shown that the number of genes with altered expression after exposure to HDAC inhibitors depends on the structure of the HDAC inhibitor, the cell line studied and the time of drug exposure $(39,40)$, functional effects of structurally unrelated HDAC inhibitors on primary AML cells are largely similar in individual patients but differ between patients.

Global gene expression profiles for patients without and with HDAC-induced growth enhancement were compared. To minimize patient heterogeneity we only included FLT3ITD $^{+}$patients with normal cytogenetics. This demonstrated that the two patient groups could not be separated based on the expression of HDACs and histone acetyl transferases, but were clearly separated by principal component analysis based on the expression of the 100 genes showing the largest variation between the two groups. This indicates that the growth enhancement observed is not dependent on differences in HDAC or histone acetyl transferase expression, but rather on differences in the molecular context of HDAC inhibition.

We investigated the effects of valproic acid and PXD101 on the levels of cytokines: i) CCL3, CXCL8 and CXCL10, which are among the chemokines most commonly released at high levels by human AML cells (41); ii) GM-CSF and IL13 , which can function as AML cell growth factors for most patients $(12,25)$; and iii) the immunomodulatory cytokines IL-6 and TNF $\alpha$. HDAC inhibitors did not significantly change cytokine levels when AML cells were cultured alone, whereas significantly increased levels were detected for IL-1ß, GMCSF, IL-6 and TNF $\alpha$ when leukaemia cells were cocultured with BMSC. Many of these cytokines can be released both by stromal and AML cells, though the increased levels were probably caused mainly by the AML cells because a similar variation between patients was seen for AML cells cultured alone as well as in cocultures. Thus, induction of growthenhancing cytokines may contribute to the drug-induced growth stimulation, but only in certain experimental models.

We compared the effect of HDAC inhibitors on proliferation of $\mathrm{CD}^{3} 4^{+} \mathrm{AML}$ cells, normal bone marrow $\mathrm{CD} 34^{+}$cells and ALL blasts. The normal CD $34^{+}$cells differed from the AML cells, as growth enhancement was observed even for the highest valproic acid concentration. This difference suggests that drug effects on AML cell populations are leukaemia associated but those on a minor subset of contaminating normal haematopoietic cells are not. Furthermore, only growth inhibition (but not increased proliferation) was observed for the primary ALL cells. Thus, neither the antiproliferative effect nor the growth enhancement caused by HDAC inhibitors is AML specific.

We conclude that HDAC inhibitors have dose-dependent effects on primary human AML cells. At high concentrations the drugs are antiproliferative and proapoptotic, while growth enhancement and antiapoptotic effects are seen for a large patient subset when testing intermediate concentrations. Basal gene expression patterns in the blasts seem to be the basis for this dichotomous response. Future studies should try to clarify whether there is a clinical relevant correlation between these in vitro differences and the in vivo antileukaemic effects of HDAC inhibitors.

\section{Acknowledgements}

This study was supported by the Norwegian Cancer Society, Helse Vest, the Grieg Foundation, the Bergen Translational Research Grant Program and the Research Council of Norway. Hua My Hoang is acknowledged for excellent assistance with DNA microarrays. PXD101 was kindly provided by Topo Target A/S (Copenhagen, Denmark).

\section{References}

1. Smith M, Barnett M, Bassan R, Gatta G, Tondini C and Kern W: Adult acute myeloid leukaemia. Crit Rev Oncol Hematol 50: 197-222, 2004.

2. Bruserud O, Stapnes C, Tronstad KJ, Ryningen A, Anensen N and Gjertsen BT: Protein lysine acetylation in normal and leukaemic haematopoiesis: HDACs as possible therapeutic targets in adult AML. Expert Opin Ther Targets 10: 51-68, 2006.

3. Anensen N, Skavland J, Stapnes C, Ryningen A, Borresen-Dale AL, Gjertsen BT and Bruserud O: Acute myelogenous leukemia in a patient with Li-Fraumeni syndrome treated with valproic acid, theophyllamine and all-trans retinoic acid: a case report. Leukemia 20: 734-736, 2006.

4. Stapnes C, Ryningen A, Gjertsen BT and Bruserud O: Treatment with valproic acid, all-trans retinoic acid (ATRA) and theophyllamine for 9 days caused a persistent increase in peripheral blood platelet counts for a patient with acute myelogenous leukemia. Acta Oncol 45: 346-349, 2006.

5. Huo $X$ and Zhang $\mathrm{J}$ : Important roles of reversible acetylation in the function of hematopoietic transcription factors. J Cell Mol Med 9: 103-112, 2005.

6. Yang XJ and Gregoire S: Class II histone deacetylases: from sequence to function, regulation, and clinical implication. Mol Cell Biol 25: 2873-2884, 2005.

7. de Ruijter AJ, van Gennip AH, Caron HN, Kemp S and van Kuilenburg AB: Histone deacetylases (HDACs): characterization of the classical HDAC family. Biochem J 370: 737-749, 2003.

8. Yoo CB and Jones PA: Epigenetic therapy of cancer: past, present and future. Nat Rev Drug Discov 5: 37-50, 2006.

9. Cimino G, Lo-Coco F, Fenu S, Travaglini L, Finolezzi E, Mancini M, Nanni M, Careddu A, Fazi F, Padula F, Fiorini R, Aloe Spiriti MA, Petti MC, Venditti A, Amadori S, Mandelli F, Pelicci PG and Nervi C: Sequential valproic acid/all-trans retinoic acid treatment reprograms differentiation in refractory and highrisk acute myeloid leukemia. Cancer Res 66: 8903-8911, 2006.

10. Bene MC, Castoldi G, Knapp W, Ludwig WD, Matutes E, Orfao A and van't Veer MB: Proposals for the immunological classification of acute leukemias. European Group for the Immunological Characterization of Leukemias (EGIL). Leukemia 9: 1783-1786, 1995 . 
11. Wheatley K, Burnett AK, Goldstone AH, Gray RG, Hann IM, Harrison CJ, Rees JK, Stevens RF and Walker H: A simple, robust, validated and highly predictive index for the determination of risk-directed therapy in acute myeloid leukaemia derived from the MRC AML 10 trial. United Kingdom Medical Research Council's Adult and Childhood Leukaemia Working Parties. Br J Haematol 107: 69-79, 1999.

12. Bruserud O, Hovland R, Wergeland L, Huang TS and Gjertsen BT: Flt3-mediated signaling in human acute myelogenous leukemia (AML) blasts: a functional characterization of Flt3-ligand effects in AML cell populations with and without genetic Flt3 abnormalities. Haematologica 88: 416-428, 2003.

13. Bruserud O, Ryningen A, Wergeland L, Glenjen NI and Gjertsen BT: Osteoblasts increase proliferation and release of pro-angiogenic interleukin 8 by native human acute myelogenous leukemia blasts. Haematologica 89: 391-402, 2004.

14. Stapnes C, Doskeland AP, Hatfield K, Ersvar E, Ryningen A, Lorens JB, Gjertsen BT and Bruserud O: The proteasome inhibitors bortezomib and PR-171 have antiproliferative and proapoptotic effects on primary human acute myelogenous leukaemia cells. Br J Haematol 136: 814-828, 2007.

15. Bruserud O, Gjertsen BT and von Volkman HL: In vitro culture of human acute myelogenous leukemia (AML) cells in serumfree media: studies of native AML blasts and AML cell lines. $J$ Hematother Stem Cell Res 9: 923-932, 2000.

16. Plumb JA, Finn PW, Williams RJ, Bandara MJ, Romero MR, Watkins CJ, La Thangue NB and Brown R: Pharmacodynamic response and inhibition of growth of human tumor xenografts by the novel histone deacetylase inhibitor PXD101. Mol Cancer Ther 2: 721-728, 2003

17. Plumb JA, Steele N, Finn PW and Brown R: Epigenetic approaches to cancer therapy. Biochem Soc Trans 32: 1095-1097, 2004.

18. Glenjen N, Ersvaer E, Ryningen A and Bruserud O: In vitro effects of native human acute myelogenous leukemia blasts on fibroblasts and osteoblasts. Int J Cancer 111: 858-867, 2004.

19. Ryningen A, Wergeland L, Glenjen N, Gjertsen BT and Bruserud O: In vitro crosstalk between fibroblasts and native human acute myelogenous leukemia (AML) blasts via local cytokine networks results in increased proliferation and decreased apoptosis of AML cells as well as increased levels of proangiogenic Interleukin 8. Leuk Res 29: 185-196, 2005.

20. Anensen N, Øyan AM, Bourdon JC, Kalland KH, Bruserud O and Gjertsen BT: A distinct p53 protein isoform signature reflects the onset of induction chemotherapy for acute myeloid leukemia. Clin Cancer Res 12: 3985-3992, 2006.

21. Øyan AM, Bo TH, Jonassen I, Gjertsen BT, Bruserud O and Kalland KH: cDNA microarray analysis of non-selected cases of acute myeloid leukemia demonstrates distinct clustering independent of cytogenetic aberrations and consistent with morphological signs of differentiation. Int J Oncol 28: 1065-1080, 2006.

22. Øyan AM, Bo TH, Jonassen I, Ulvestad E, Gjertsen BT, Kalland $\mathrm{KH}$ and Bruserud O: CD34 expression in native human acute myelogenous leukemia blasts: differences in CD34 membrane molecule expression are associated with different gene expression profiles. Cytometry B Clin Cytom 64: 18-27, 2005 .

23. Gore SD: Combination therapy with DNA methyltransferase inhibitors in hematologic malignancies. Nat Clin Pract Oncol 2 (suppl 1): S30-S35, 2005.

24. Kuendgen A, Schmid M, Schlenk R, Knipp S, Hildebrandt B, Steidl C, Germing U, Haas R, Dohner $\mathrm{H}$ and Gattermann N: The histone deacetylase (HDAC) inhibitor valproic acid as monotherapy or in combination with all-trans retinoic acid in patients with acute myeloid leukemia. Cancer 106: 112-119, 2006.

25. Bruserud O, Gjertsen BT, Foss B and Huang TS: New strategies in the treatment of acute myelogenous leukemia (AML): in vitro culture of aml cells - the present use in experimental studies and the possible importance for future therapeutic approaches. Stem Cells 19: 1-11, 2001.
26. Ryningen A, Stapnes C and Bruserud O: Clonogenic acute myelogenous leukemia cells are heterogeneous with regard to regulation of differentiation and effect of epigenetic pharmacological targeting. Leuk Res 31: 1311-1321, 2007.

27. Bullinger L, Dohner K, Bair E, Frohling S, Schlenk RF, Tibshirani R, Dohner H and Pollack JR: Use of gene-expression profiling to identify prognostic subclasses in adult acute myeloid leukemia. N Engl J Med 350: 1605-1616, 2004.

28. Tagliafico E, Tenedini E, Manfredini R, Grande A, Ferrari F, Roncaglia E, Bicciato S, Zini R, Salati S, Bianchi E, Gemelli C, Montanari M, Vignudelli T, Zanocco-Marani T, Parenti S, Paolucci P, Martinelli G, Piccaluga PP, Baccarani M, Specchia G, Torelli U and Ferrari S: Identification of a molecular signature predictive of sensitivity to differentiation induction in acute myeloid leukemia. Leukemia 20: 1751-1758, 2006.

29. Raffoux E, Chaibi P, Dombret H and Degos L: Valproic acid and all-trans retinoic acid for the treatment of elderly patients with acute myeloid leukemia. Haematologica 90: 986-988, 2005.

30. Monneret C: Histone deacetylase inhibitors. Eur J Med Chem 40: 1-13, 2005.

31. Drummond DC, Noble CO, Kirpotin DB, Guo Z, Scott GK and Benz CC: Clinical development of histone deacetylase inhibitors as anticancer agents. Annu Rev Pharmacol Toxicol 45: 495-528, 2005.

32. Kuendgen A, Knipp S, Fox F, Strupp C, Hildebrandt B, Steidl C, Germing U, Haas R and Gattermann N: Results of a phase 2 study of valproic acid alone or in combination with all-trans retinoic acid in 75 patients with myelodysplastic syndrome and relapsed or refractory acute myeloid leukemia. Ann Hematol 84 Suppl 13: 61-66, 2005.

33. Sandor V, Bakke S, Robey RW, Kang MH, Blagosklonny MV, Bender J, Brooks R, Piekarz RL, Tucker E, Figg WD, Chan KK, Goldspiel B, Fojo AT, Balcerzak SP and Bates SE: Phase I trial of the histone deacetylase inhibitor, depsipeptide (FR901228, NSC 630176), in patients with refractory neoplasms. Clin Cancer Res 8: 718-728, 2002.

34. Bug G, Ritter M, Wassmann B, Schoch C, Heinzel T, Schwarz K, Romanski A, Kramer OH, Kampfmann M, Hoelzer D, Neubauer A, Ruthardt M and Ottmann OG: Clinical trial of valproic acid and all-trans retinoic acid in patients with poorrisk acute myeloid leukemia. Cancer 104: 2717-2725, 2005.

35. Garcia-Manero G, Kantarjian HM, Sanchez-Gonzalez B, Yang H, Rosner G, Verstovsek S, Rytting M, Wierda WG, Ravandi F, Koller C, Xiao L, Faderl S, Estrov Z, Cortes J, O'Brien S, Estey E, Bueso-Ramos C, Fiorentino J, Jabbour E and Issa JP: Phase 1/2 study of the combination of 5-aza-2'-deoxycytidine with valproic acid in patients with leukemia. Blood 108: 3271-3279, 2006

36. Sanz MA and Lo Coco F: Standard practice and controversial issues in front-line therapy of acute promyelocytic leukemia. Haematologica 90: 840-845, 2005.

37. Seiter K, Feldman EJ, Dorota Halicka H, Deptala A, Traganos F, Burke HB, Hoang A, Goff H, Pozzuoli M, Kancherla R, Darzynkiewicz Z and Ahmed T: Clinical and laboratory evaluation of all-trans retinoic acid modulation of chemotherapy in patients with acute myelogenous leukaemia. Br J Haematol 108: 40-47, 2000 .

38. Cosio BG, Tsaprouni L, Ito K, Jazrawi E, Adcock IM and Barnes PJ: Theophylline restores histone deacetylase activity and steroid responses in COPD macrophages. J Exp Med 200: 689-695, 2004.

39. de Ruijter AJ, Meinsma RJ, Bosma P, Kemp S, Caron HN and van Kuilenburg AB: Gene expression profiling in response to the histone deacetylase inhibitor BL1521 in neuroblastoma. Exp Cell Res 309: 451-467, 2005.

40. Van Lint C, Emiliani S and Verdin E: The expression of a small fraction of cellular genes is changed in response to histone hyperacetylation. Gene Expr 5: 245-253, 1996.

41. Bruserud O, Ryningen A, Olsnes AM, Stordrange L, Øyan AM, Kalland KH and Gjertsen BT: Subclassification of patients with acute myelogenous leukemia based on chemokine responsiveness and constitutive chemokine release by their leukemic cells. Haematologica 92: 332-341, 2007. 